\title{
Screening for mutations in two exons of FANCG gene in Pakistani population
}

\author{
Ujala Aymun ${ }^{\mathrm{a}, \mathrm{b}}$, Saima Irama ${ }^{\mathrm{a},}$, Iram Aftaba , Saba Khaliq ${ }^{\mathrm{d}}$, Nadir Alie, Nisar Ahmedf, Shahida Mohsin ${ }^{\mathrm{a}}$
}

\begin{abstract}
Background. Fanconi anemia is a rare autosomal recessive disorder of genetic instability. It is both molecularly and clinically, a heterogeneous disorder. Its incidence is 1 in 129,000 births and relatively high in some ethnic groups. Sixteen genes have been identified among them mutations in FANCG gene are most common after FANCA and FANCC gene mutations.
\end{abstract}

Objective. To study mutations in exon 3 and 4 of FANCG gene in Pakistani population.

Methods. Thirty five patients with positive Diepoxybutane test were included in the study. DNA was extracted and amplified for exons 3 and 4. Thereafter Sequencing was done and analyzed for the presence of mutations.

Results. No mutation was detected in exon 3 whereas a carrier of known mutation c.307+1 G>T was found in exon 4 of the FANCG gene.

Conclusion. Absence of any mutation in exon 3 and only one heterozygous mutation in exon 4 of FANCG gene points to a different spectrum of FA gene pool in Pakistan that needs extensive research in this area.

Key words: Fanconi anemia, FANCG gene, screening for mutation, diepoxybutane test

Received: November 9, 2016; Accepted with revision: May 29, 2017; Available online: June 12, 2017

https://doi.org/10.5507/bp.2017.030

${ }^{a}$ Department of Hematology, University of Health Sciences, Lahore, Pakistan

${ }^{b}$ Department of Pathology, Avicenna Medical College, Lahore, Pakistan

'Department of Pathology, Bolan Medical College, Quetta, Pakistan

${ }^{d}$ Department of Physiology and Cell Biology, University of Health Sciences, Lahore, Pakistan

eDepartment of Hematology, Armed Forces institute of Pathology, Rawalpindi, Pakistan

fDepartment of Hematology, Children Hospital Lahore, Pakistan

Corresponding author: Saima Iram, e-mail:drsaimairam15@yahoo.com

\section{INRODUCTION AND LITERATURE REVIEW}

Fanconi anemia is a rare autosomal recessive disorder. Genomic instability is the characterstic feature of this disease and is manifested both at cellular level and clinically ${ }^{1}$. Cellular manifestations of genetic instability include chromosomal breakage, cell cycle disturbance and increased rate of somatic mutations while phenotypic manifestations include growth retardation, congenital malformations, bone marrow failure, high risk of neoplasia and premature aging ${ }^{2}$. Sixteen FA genes have been identified to date. Each of these corresponds to a different complementation group named as FANCA, -B, -C, -D1, -D2, -E, -F, -G, -I, -J, - - $,-\mathrm{M},-\mathrm{N},-\mathrm{O},-\mathrm{P}$ and -Q. These gene take part in the maintenance of genomic stability through Fanconi anemia pathway. A defect in the FA pathway arises due to mutations in any one of the sixteen genes ${ }^{3}$. FA is the most common inherited form of aplastic anemia ${ }^{4}$. The carrier frequency of Fanconi anemia is recently reported to be 1 in 181 that is $30 \%$ higher than the previously reported frequency of 1 in 300 in the American population. The incidence in heterozygotes is 1 in 129,000 births $^{5}$.

Clinically, Fanconi anemia is characterized by the presence of congenital physical anomalies, bone marrow failure and a predisposition to develop myeloid neoplasms and solid tumors ${ }^{6}$. The mean age for the onset of disease is seven years $1: 1$ male and female ratio ${ }^{7}$. Congenital physical anomalies include skin pigmentation, radial ray defects and other skeletal malformations, malformations involving the eyes, gastrointestinal tract, genitourinary tract, heart, oral cavity and central nervous system ${ }^{8}$. Approximately 30\% patients present with no physical anomaly ${ }^{9}$. Hematologic abnormalities are the most common features of the Fanconi anemia present in $98 \%$ of patients. Severity of hematologic abnormality varies from single cytopenia to pancytopenia. The first encountered abnormality after birth is often macrocytosis followed by thrombocytopenia. Patients show features of stressed hematopoiesis such as raised $\mathrm{MCV}$ and $\mathrm{HbF}\left(\right.$ ref. $\left.^{10}\right)$. FA patients have a greater predisposition to develop squamous cell cancer (SCC) of head \& neck, esophagus, female genital tract and certain liver tumors. It has been observed that there is 4.4 fold higher risk of developing SCC in patients who have undergone bone marrow transplantation ${ }^{11}$.

The Fanconi Anemia pathway is a highly complex DNA repair pathway, activated in response to DNA damage to repair interstrand crosslinks (ICLs) during S-phase of the cell cycle ${ }^{12}$. The central event in the pathway is the monoubiquitination of FANCD2, one of the FA proteins. Ubiquitination is the process where a small protein ubiquitin covalently bonds to the target protein. More than half of FA proteins (FANCA, FANCB, FANCC, FANCE, FANCF, FANCG, FANCM and FANCL) are required for the monoubiquitination of FANCD2. All these proteins together form FA core complex ${ }^{13}$. Ubiquitinated FANCD2-FANCI complex (ID-complex) localizes to the nuclear foci at the site of DNA damage. Nuclear foci are 
structures that form at the site of DNA damage and are directly involved in the DNA repair mechanism. ID-complex recruits endonucleases such as FANCQ and ERCC1 to the ICLs for the DNA repair ${ }^{14}$. FANCD1, FANCJ and FANCN take part in repair downstream the ID complex ${ }^{15}$. In normal circumstances, FA pathway is set off by default, but it is rapidly activated when required. After completion of DNA repair, it is inactivated again. FA pathway is often restricted to S-phase of the cell cycle ${ }^{16}$.

FANCG (OMIM \# 602956) previously known as XRCC9, was first identified in Chinese hamster ovary (CHO) mutant UV40 cell line ${ }^{17}$. Its cytogenetic location is 9 p 13.3 and consists of 6,182 bases and 14 exons. It encodes a protein of mol. wt. 70kDa and 622 amino acids. FANCG is a constituent of the FA core complex. Structurally, it consists of seven tetratricopeptide repeat motifs (TPRs). The TPRs are important for assembly of core complex proteins ${ }^{18}$. FANCG is a phosphoprotein and phosphorylation occurs at serines 7, 383 and 387. Phosphorylation is thought to be important for cellular resistance to DNA crosslinks ${ }^{19}$. It interacts with FANCD2, BRCA2 and XRCC3 in another pathway known as Homologous - recombination pathway. This pathway is involved in resolving the double stranded breaks ${ }^{20}$. It causes disease by both homozygous and compound heterozygous mutations. FANCG is the third most common type of FA accounting for at least $10 \%$ of patients. Pathogenic variants in this gene are highly variable. Although, some alleles have been found more commonly in certain populations, for instance, c. $307+1 \mathrm{G}>\mathrm{C}$ is more frequently present in Japanese \& Korean population ${ }^{21}$, c.925-2A>Gin Brazilian population, c. $1480+1 \mathrm{G}>\mathrm{C}$ in French Canadian population $^{22,23}$ and c.637-643delTACCGCC in South African blacks ${ }^{24}$. Mutations in all 14 exons of FANCG have been reported. At least 35 patients have been reported with mutations in exon 3 and 10 patients with mutations in exon 4 (International Fanconi Anemia Mutation Database, accessed on 29-10-14). Seven mutations have been described in exon 3 including c.179delT (ref. ${ }^{24}$ ), c.212 T>C (ref. $\left.{ }^{22}\right)$, c.219_220insT, c.244dupG $\left(\right.$ ref. $\left.^{25}\right)$, c. 246 delA (ref. ${ }^{24}$ ), c.271_272del $\left(\right.$ ref. $^{26}$ ), c. $307+1 G>C$ $\left(\right.$ ref. $\left.^{25}\right)$. Only 2 pathogenic variants have been described in exon 4 including c.313G $>\mathrm{T}$ ( ref. $^{25}$ ) and c.346_347del $\left(\right.$ ref. $\left.^{22}\right)$.

\section{METHODOLOGY}

\section{Study subjects}

Genomic DNA samples were taken from individuals diagnosed with FA, following written informed consent. These studies were approved by the Institutional Review Board of the University of Health Sciences, Lahore. Genomic DNA was isolated from peripheral blood. Phenol/chloroform extraction and ethanol precipitation was used for the preparation of DNA. A total of 50 patients on the basis of clinical suspicion were initially recruited. The chromosomal breakage analysis came positive in 35 of them. Both male and female patients of all ages were included in the study. Patient biodata, family history, history of disease, general physical examination and laboratory findings were recorded in an intricately designed proforma.

\section{Chromosomal breakage test}

Chromosome breakage study was done using Phytohemagglutinin (PHA) stimulated lymphocyte cultures induced with Mitomycin C (MMC) with final concentration of $0.01 \mathrm{mg} / \mathrm{mL}$ and incubated at $37{ }^{\circ} \mathrm{C}$ for 72 h. Cells were arrested with colchicine at metaphase stage, followed by hypotonic solution treatment with $10 \%$ potassium chloride, and cells were fixed with fixative (3:1 methanol: glacial acetic acid). At least 4 slides per culture were prepared by dropping suspension of cells in a tube on frosted slides and stained with Giemsa stain. A total of 20-25 metaphases per slide were scored under bright field microscope and chromosomal breakages and radial forms were recorded and compared with the negative control (or non-FA) sample each time.

\section{Mutation screening of $F A N C G$ gene}

Genomic DNA was extracted from peripheral blood using standard phenol chloroform method ${ }^{27}$.

PCR was done using $1 \mu \mathrm{L}$ DNA template, 10X standard Taq Reaction Buffer $(2.5 \mu \mathrm{L}), 10 \mathrm{mM}$ dNTPs $(1 \mu \mathrm{L})$, $10 \mu \mathrm{M}$ forward primer $(1 \mu \mathrm{L}), 10 \mu \mathrm{M}$ reverse primer $(1$ $\mu \mathrm{L})$, Taq DNA Polymerase $(0.3 \mu \mathrm{L}), \mathrm{MgCl}_{2}(2.5 \mu \mathrm{L})$ and Nuclease free water $(15.7 \mu \mathrm{L})$ at annealing temperature of $62{ }^{\circ} \mathrm{C}$ for exon 3 and $58^{\circ} \mathrm{C}$ for exon 4 .

Primers described elsewhere were used for the purpose of amplification as well as sequencing. Amplification products were analyzed using agarose gel electrophoresis and subjected to fluorescence based chain terminator sequencing method using Dye Terminator Cycle sequencing quick start kit (EN 608120) and were analyzed by CEQ TM 8000 Genome Lab TM series Genetic Analysis System (Beckman Coulter). Sequences were evaluated using ensemble genome browser ENSG00000221829 and aligned to the human reference genome build hg 18 (NCBI36.1) using BLAST program (www.genome.ucsc.edu).

\section{RESULTS}

The study included 35 (17M: $18 \mathrm{~F})$ patients ranging in age from 4 years to 20 years. History of consanguinity was present in $69 \%$ of the patients. Low birth weight was observed in $21(60 \%)$ patients. Short stature was observed in $26(74.3 \%)$ patients. Skin abnormalities were present in $11(31.4 \%)$ patients, all having café-au-lait spots as skin manifestation. Skeletal abnormalities were observed in $17(48.6 \%)$ patients, 9 of which had hypoplastic thumb

Table 1. Baseline laboratory findings of patients.

\begin{tabular}{ll}
\hline Laboratory parameter & Median (range) \\
\hline $\mathrm{Hb}(\mathrm{g} / \mathrm{dL})$ & $8.26(3.80-13.80)$ \\
$\mathrm{WBCs}\left(\mathrm{x} 10^{9} / \mathrm{L}\right)$ & $3.19(0.90-9.1)$ \\
Platelets $\left(\mathrm{x} 10^{9} / \mathrm{L}\right)$ & $72.34(150.0-320.0)$ \\
\hline
\end{tabular}


and 8 had bifid thumb. Microcephaly was observed in $19(54.3 \%)$ patients. Microphthalmia was observed in 20 (57.1\%) patients. Renal abnormalities were present in 4 (11.4\%) patients. Of these, 3 had absent one kidney and 1 patient had bifid ureter.

As far as hematological manifestations are concerned, recurrent infections were the most common finding present in all the patients, followed by pallor in $91.4 \%$ of patients and then epistaxis in $54.3 \%$ of the patients. Baseline laboratory hematological findings are given in table 1.

\section{Molecular findings}

Sequencing of exon 3 was carried out to screen for the mutation c. $307+1 \mathrm{G}>\mathrm{T}$, which is the most prevalent mutation in Japanese and Korean population and also found in 2 patients of Iranian ethnicity recently ${ }^{28,29}$. Sequencing analysis of exon 3 revealed no sequence alteration in our cohort of patients.

Sequencing of exon 4 was carried out to screen the mutation c. $313 \mathrm{G}>\mathrm{T}$, which is the founder mutation in the German population. One of our patients was found to be heterozygous for this mutation. This patient was a female patient of 12 years of age diagnosed with FA at the age of eight years. She did not have any congenital physi- cal abnormality and did not belong to a consanguineous pedigree, but she had low birth weight and short stature.

\section{DISCUSSION}

Fanconi anemia is the most common cause of congenital aplastic anemia. Due to its genetic and clinical heterogeneity, it has been a disease of great interest for researchers throughout the world ${ }^{30}$. Before the molecular era began, all the research regarding Fanconi anemia was directed towards its phenotypic appearance, but after 1990, most of the research has been focused on the genetics of Fanconi anemia. Sixteen different genes have been discovered to be involved in the pathogenesis of this disease. FANCG is the third most common gene involved in the pathogenesis of FA, first two being FANCA and FANCC respectively ${ }^{31}$.

After a thorough literature review and to the best of our knowledge, this gene has never been probed before in Pakistan. The prevalence of this gene has been found to be variable in different populations. For example, it is around $10 \%$, according to the IFAR (FA registry) developed in America ${ }^{8}$ and $9 \%$ in a study done in Italy $^{31}$.

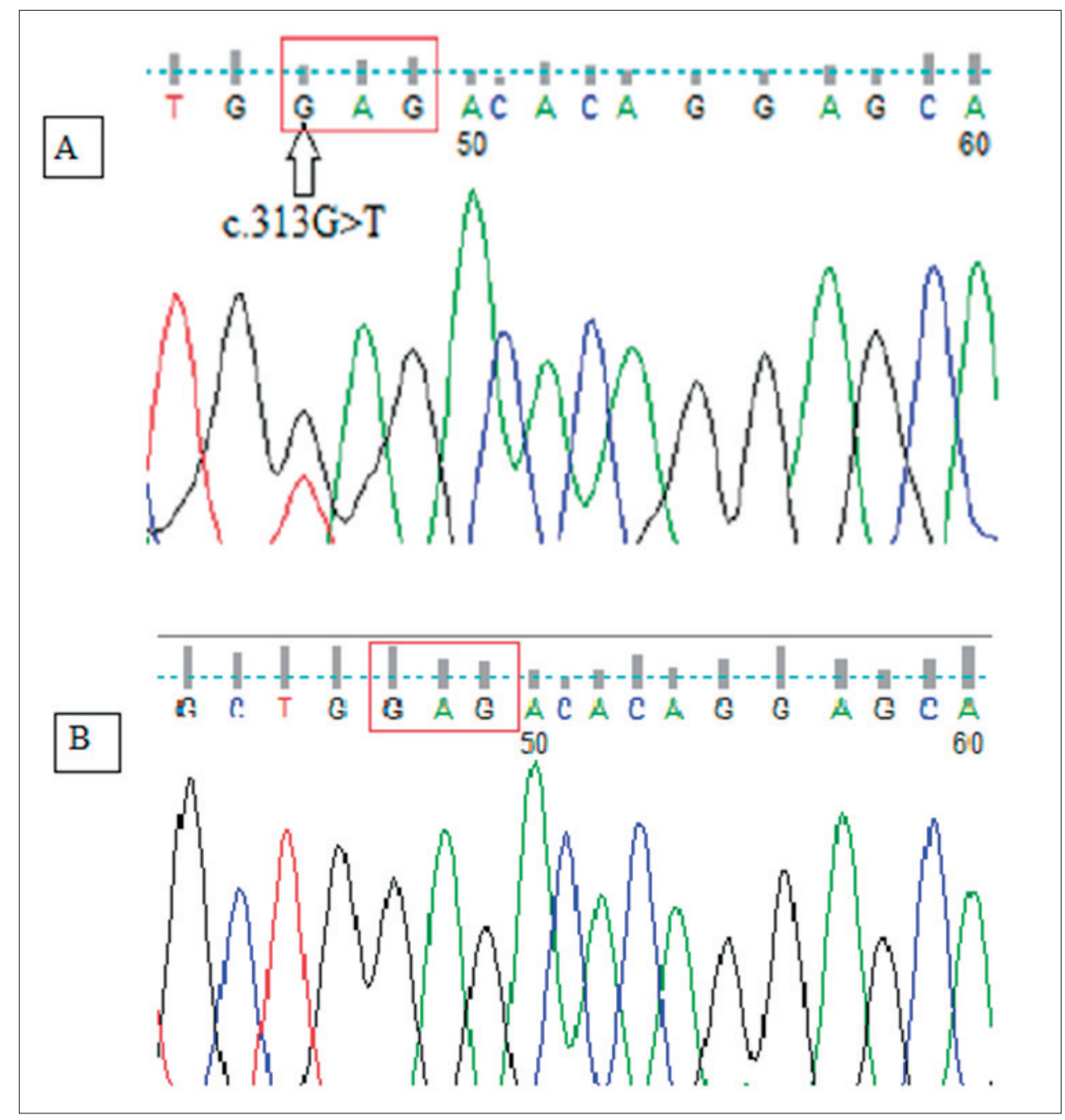

Fig. 1. Electropherogram showing sequencing of exon 4, A shows heterozygous mutation in patient FA-17 by arrow head, B shows the normal sequence in a control 
However, it has been found to be much higher in some populations due to founder effects of certain mutations. For instance, the incidence of FANCG has been reported to be $77.5-82 \%$ due to the common founder mutation of c.637-643delTACCGCC in South African blacks ${ }^{24}$. This trend of variance in the prevalence of FA genes exists for all FA genes. For example, Ashkenazi Jews have the $F A N C C$ as the most prevalent genetic mutation because of the founder effect of IVS4 $+4 \mathrm{~A}>\mathrm{T}$ mutation ${ }^{32}$. A study done recently in Egypt on four exons of FANCA gene has revealed no mutation found to the researchers' surprise as FANCA is the most prevalent gene throughout the world so far $^{33}$. FANCA has also been the most prevalent mutation found in our neighboring country India whereas FANCG has not been reported in any study done yet ${ }^{34-37}$.

Researchers from our institution have already worked on FANCA and FANCC genes. Their work has shown FANCA mutations in $47 \%$ of patients and FANCC in $72 \%$ of patients $^{38}$. So we decided to take up the third most prevalent gene i.e., FANCG. This gene comprises of fourteen exons. Mutations have been reported in all of them. Most frequently found mutation in this gene is c.307+1G>T mutation (Fanconi anemia data base accessed on $27^{\text {th }}$ March 2016 http://www.rockefeller.edu/fanconi/genes/jumpg). This is also the founder mutation in Japanese and Korean populations and is found to have a common ancestor haplotype in East Asia $^{39}$. This mutation is also reported in 2 patients from Iran $^{29}$. Therefore, taking into consideration the prevalence of this mutation in Asian countries and especially in Iran, it was decided to probe into this mutation in our country. However, we did not find this mutation in any of our patients in homozygous or in the heterozygous state. Another common mutation is c. $313 \mathrm{G}>\mathrm{T}$, which is also a founder mutation in a German population ${ }^{21}$. In our study, we found a heterozygous c.313G $>$ T mutation.

This variance in prevalence of gene mutations can be explained on two bases. Firstly, that we have sequenced only two exons of the FANCG gene, whereas others have studied all fourteen exons. Secondly, this heterogeneity can also be due to difference in geographic and ethnic origin as Indians have also not found any FANCG mutation to date.

As far as the phenotype of FA is concerned, it is a phenotypically heterogeneous disease. Each patient of FA is presented with a unique set of physical characteristics. Median age at diagnosis in our study is 11 years with a range of 4-20 years similar to the finding of Solomon et. al., conducted in India. However, this finding is exceptionally different from studies done in western countries where the median age at diagnosis is 6 years ${ }^{40}$. This difference is indicating the trend of late diagnosis of FA in Southeast Asia. Boost in the knowledge of physicians about the physical findings of FA is needed to enable them to make early diagnosis because most of the patients in our country present when there is bone marrow failure.

Despite clinically well documented congenital and somatic physical abnormalities, most of the patients of FA present with bone marrow failure ${ }^{41}$. The most common presenting complaint in our cohort of patients has been recurrent infections (present in $100 \%$ of patients) and bleeding tendencies (present in $82 \%$ of patients) with the most frequent site of the bleeding being nose. This finding is consistent with most other publications ${ }^{32,37}$. Pallor is also a very frequent finding in most studies done worldwide $^{40}$. We also observed pallor in more than $50 \%$ of patients. Although, bleeding tendency and recurrent infections are manifestations of thrombocytopenia and neutropenia, we found anemia to be more severe in our patients at the time of diagnosis consistent with the finding of Feben et al. Most of our patients came with severe aplastic anemia at first presentation. This finding is similar to the most other publications ${ }^{37}$.

Hematologic malignancies and solid tumors are a frequent finding in Fanconi anemia patients and a lot of work has been done on this aspect ${ }^{6,42}$. We did not find any patient with hematologic or solid tumors. Most of the studies done on malignancies found in FA were retrospective or a long term follow-up studies, whereas our study was a descriptive study and purposive sampling was done. Our study did not include any long term follow-up. Moreover, solid tumors tend to develop later in the course of disease. Median age of onset of solid tumors is around 30 years in literature ${ }^{43}$. But in our part of world patients hardly cross the age of 20 years, mainly because of limited availability of bone marrow transplant and other health facilities. It is reported that there is a $13 \%$ chance of developing AML in patients of FA by age 50 with a maximum number of patients between 15 and 35 years $^{44}$. Our patients had a median age of 11 years, too young to show such development.

\section{CONCLUSION}

We report the presence of one heterozygous patient carrying c. $313 \mathrm{G}>\mathrm{T}$ mutation in FANCG gene.

This is the first report of FANCG gene mutation in Pakistan that is confirmed molecularly. We have also described the phenotypic presentation of FA patients in our country. Current study also revealed that most of the patients in Pakistan seek for medical aid very late and diagnosed as patients of Fanconi anemia when they have developed complications due to bone marrow failure.

\section{Limitations}

Financial and time restraints were the major limitation of our research.

Our study includes $35 \mathrm{FA}$ patients, which is a small sample size. However, given the rarity of the disease, this sample size was deemed adequate for the research.

Our study mostly includes patients who presented to the hospital for severe cytopenias, thus they represent the severe spectrum of the disease. So our data do not truly represent the phenotype of the disease.

Author contributions: UA: sample collection, experiment, data analysis and manuscript writing; SI: sample collection, writing and proof reading of manuscript; IA: sample collection and manuscript writing. SK: study planning, experiment and data analysis. NA, NiA: sample collection, 
clinical assessment of the patients and experiment; SM: conception, planning and execution of the study.

Conflict of interest statement: None declared.

\section{REFERENCES}

1. Mitchell R, Wagner JE, Hirsch B, DeFor TE, Zierhut H, MacMillan ML. Haematopoietic cell transplantation for acute leukaemia and advanced myelodysplastic syndrome in Fanconi anaemia. Brit $J$ Haematol 2014;164(3):384-95.

2. Deaconu A, Vodă D, Bulucea D. Fanconi Anemia-Case Report of Rare Aplastic Anemia at Child. Acta Medica Marisiensis 2014;60(3):125-8

3. Soulier J. Fanconi anemia. In: ASH Education Program Book. 2011. p. 492-497.

4. Tsangaris $E$, Klaassen R, Fernandez CV, Yanofsky R, Shereck E, Champagne J, Silva M, Lipton JH, Brossard J, Michon B, Abish S. Genetic analysis of inherited bone marrow failure syndromes from one prospective, comprehensive and population-based cohort and identification of novel mutations. J Med Genet 2011;48(9):618-28.

5. Rosenberg PS, Tamary H, Alter BP. How high are carrier frequencies of rare recessive syndromes? Contemporary estimates for Fanconi Anemia in the United States and Israel. Am J Med Genet 2011;155(8):1877-83.

6. Rosenberg PS, Alter BP, Ebell W. Cancer risks in Fanconi anemia: findings from the German Fanconi Anemia Registry. Haematologica 2008;93(4):511-7.

7. Kutler DI, Singh B, Satagopan J, Batish SD, Berwick M, Giampietro PF, Hanenberg H, Auerbach AD. A 20-year perspective on the International Fanconi Anemia Registry (IFAR). Blood 2003;101(4):1249-56.

8. Auerbach AD. Fanconi anemia and its diagnosis. Mutat Res 2009;668(1):4-10.

9. Dokal I, Vulliamy T. Inherited aplastic anaemias/bone marrow failure syndromes. Blood Rev 2008;22(3):141-53.

10. Butturini A, Gale RP, Verlander PC, Adler-Brecher B, Gillio AP, Auerbach, AD. Hematologic abnormalities in Fanconi anemia: an International Fanconi Anemia Registry study. Blood 1994;84(5):1650 5.

11. Rosenberg PS, Socié G, Alter BP, Gluckman E. Risk of head and neck squamous cell cancer and death in patients with Fanconi anemia who did and did not receive transplants. Blood 2005;105(1):67-73.

12. Ceccaldi R, Parmar K, Mouly E, Delord M, Kim JM, Regairaz M, Pla M, Vasquez N, Zhang QS, Pondarre C, De Latour RP. Bone marrow failure in Fanconi anemia is triggered by an exacerbated p53/p21 DNA damage response that impairs hematopoietic stem and progenitor cells. Cell Stem Cell 2012;11(1):36-49.

13. Taniguchi T, D'Andrea AD. Molecular pathogenesis of Fanconi anemia: recent progress. Blood 2006;107(11):4223-33.

14. Selenti N, Kattamis A, Kanavakis E, Kitsiou S, Mavrou A. Genetic Diagnosis of Fanconi Anemia. J Hematol Blood Transfus Disord 2015;1:1.

15. Wu Y, Sommers JA, Suhasini AN, Leonard T, Deakyne JS, Mazin AV Shin-ya K, Kitao H, Brosh RM. Fanconi anemia group J mutation abolishes its DNA repair function by uncoupling DNA translocation from helicase activity or disruption of protein-DNA complexes. Blood 2010;116(19):3780-91.

16. Peng M, Xie J, Ucher A, Stavnezer J, Cantor SB. Crosstalk between BRCA-Fanconi anemia and mismatch repair pathways prevents MSH2-dependent aberrant DNA damage responses. The EMBO J 2014;33(15):1698-712.

17. Liu JM, Young NS, Walsh CE, Cottier-Fox M, Carter C, Dunbar C, Barrett AJ, Emmons R. Retroviral Mediated Gene Transfer of the Fanconi Anemia Complementation Group C Gene to Hematopoietic Progenitors of Group C Patients. National Institutes of Health, Bethesda, Maryland. Hum Gene Ther 1997;8(14):1715-30.

18. Wilson JB, Yamamoto K, Marriott AS, Hussain S, Sung P, Hoatlin ME, Mathew CG, Takata M, Thompson LH, Kupfer GM, Jones NJ. FANCG promotes formation of a newly identified protein complex containing BRCA2, FANCD2 and XRCC3. Oncogene 2008;27(26):3641-52.

19. Futaki M, Watanabe S, Kajigaya S, Liu J M. Fanconi anemia protein, FANCG, is a phosphoprotein and is upregulated with FANCA after TNF-a treatment. Biochem Biophys Res Commun 2001;281(2):347-51.
20. Van de Vrugt HJ, Koomen M, Bakker S, Berns MA, Cheng NC, van der Valk MA, de Vries Y, Rooimans MA, Oostra AB, Hoatlin ME, te Riele $\mathrm{H}$. Evidence for complete epistasis of null mutations in murine Fanconi anemia genes Fanca and Fancg. DNA Repair (Amst) 2011;10(12):1252-61.

21. Yagasaki H, Oda T, Adachi D, Nakajima T, Nakahata T, Asano S, Yamashita T. Two common founder mutations of the fanconi anemia group G gene FANCG/XRCC9 in the Japanese population. Hum Mutat 2003;21(5):555.

22. Demuth I, Wlodarski M, Tipping AJ, Morgan NV, de Winter JP, Thiel M, GräsI S, Schindler D, D D'Andrea A, Altay C, Kayserili H. Spectrum of mutations in the Fanconi anaemia group G gene, FANCG/XRCC9. Eur J Hum Genet 2000;8(11):861.

23. Nakanishi K, Moran A, Hays T, Kuang Y, Fox E, Garneau D, De Oca RM, Grompe M, D D'Andrea A. Functional analysis of patient-derived mutations in the Fanconi anemia gene, FANCG/XRCC9. Exp Hematol 2001;29(7):842-9.

24. Wainstein T, Kerr R, Mitchell CL, Madaree S, Essop FB, Vorster E, Wainwright R, Poole J, Krause A. Fanconi anaemia in black South African patients heterozygous for the FANCG c. 637-643delTACCGCC founder mutation. SAMJ 2013;103(12):970-3.

25. Auerbach AD, Greenbaum J, Pujara K, Batish SD, Bitencourt MA, Kokemohr I, Schneider H, Lobitzc S, Pasquini R, Giampietro PF, Hanenberg $\mathrm{H}$. Spectrum of sequence variation in the FANCG gene: an International Fanconi Anemia Registry (IFAR) study. Hum mutat 2003;21(2):158-68.

26. Ameziane N, Errami A, Léveillé $F$, Fontaine $C$, de Vries $Y$, van Spaendonk RM, de Winter JP, Pals G, Joenje H. Genetic subtyping of Fanconi anemia by comprehensive mutation screening. Hum mutat 2008;29(1):159-66.

27. Sambrook J, Russell DW. Preparation and analysis of eukaryotic genomic DNA molecular cloning. Cold Harbor Laboratory Press, New York. 2001:6-4.

28. Park J, Chung NG, Chae H, Kim M, Lee S, Kim Y, Lee JW, Cho B, Jeong DC, Park IY. FANCA and FANCG are the major Fanconi anemia genes in the Korean population. Clinical genetics 2013;84(3):271-5.

29. Gille JJ, Floor K, Kerkhoven L, Ameziane N, Joenje H, de Winter JP. Diagnosis of Fanconi anemia: mutation analysis by multiplex ligation-dependent probe amplification and PCR-Based sanger sequencing. Anemia 2012;2012:603253. doi: 10.1155/2012/603253

30. Lee HJ, Park S, Kang HJ, Jun JK, Lee J, Lee DS, Park SS, Seong MW. A case report of Fanconi anemia diagnosed by genetic testing followed by prenatal diagnosis. Ann Lab Med 2012;32(5):380-4.

31. De Rocco D, Bottega R, Cappelli E, Cavani S, Criscuolo M, Nicchia E, Corsolini F, Greco C, Borriello A, Svahn J, Pillon M. Mecucci C, Casazza G, Verzegnassi F, Cugno C, Locasciulli A, Farruggia P, Longoni D, Ramenghi U, Barberi W, Tucci F, Perrotta S, Grammatico P, Hanenberg H, Della Ragione F, Dufour C, Savoia A; Bone Marrow Failure Study Group of the Italian Association of Pediatric OncoHematology.Molecular analysis of Fanconi anemia: the experience of the Bone Marrow Failure Study Group of the Italian Association of Pediatric Onco-Hematology. Haematologica. 2014;99(6):102231. doi: 10.3324/haematol.2014.104224. Erratum in: Haematologica 2014;99(9):1532.

32. Feben C, Kromberg J, Wainwright R, Stones D, Poole J, Haw T, Krause A. Hematological consequences of a FANCG founder mutation in Black South African patients with Fanconi anemia. Blood Cells Mol Dis 2015;54(3):270-4.

33. Salem AM, El-Bassyouni HT, El-Kamah GY, Zarouk WA, Eid MM, Mosaad RM, Sayed AA, Temtamy SA. Screening for common mutations in four FANCA gene exons in Egyptian Fanconi anemia patients. Middle East J of Med Genet 2014;3(1):24-30.

34. Solomon $P$ J, Margaret $P$, Rajendran R, Ramalingam R, Menezes GA, Shirley AS, Lee SJ, Seong MW, Park SS, Seol D, Seo SH. A case report and literature review of Fanconi Anemia (FA) diagnosed by genetic testing. Ital J Pediatr 2015;41:38.

35. Arthur NBJ, Ganapule AP, Palani D, Viswabandya A, Mathews V, Abraham A, Srivastava VM, Srivastava A, George B, Velayudhan SR. Clinical and Molecular Characterization of Fanconi Anemia. An Indian Perspective. 56th ASH Annual Meeting and Exposition 2014. Session: 508. Bone marrow failure: Poster II. \#2938.

36. Vundinti BR. Chromosomal instability and molecular mutations in multi spectrum disease of Fanconi anemia. Mol Cytogenet $2014 ; 7(1): 1$ 
37. Chowdhry M, Makroo RN, Srivastava P, Kumar M, Sharma S, Bhadauria P, Mahajan A. Clinicohematological correlation and chromosomal breakage analysis in suspected Fanconi anemia patients of India. Indian J Med Paediatr Oncol 2014;35(1):21.

38. Aftab I, Irum S, Khaliq S, Israr M, Ali N, Jahan S, Hussain S, Mohsin S. Analysis of FANCC gene mutations (IVS4+4A>T, del322G, and $\mathrm{R} 548 \mathrm{X}$ ) in patients with Fanconi anemia in Pakistan. Turk J Med Sci 2017;47(2):391-8.

39. Park J, Kim M, Jang W, Chae H, Kim Y, Chung NG, Lee JW, Cho B, Jeong DC, Park IY, Park MS. Founder Haplotype Analysis of Fanconi Anemia in the Korean Population Finds Common Ancestral Haplotypes for a FANCG Variant. Ann Hum Genet 2015;79(3):153-61.

40. Yoon BG, Kim HN, Han UJ, Jang HI, Han DK, Baek HJ, Hwang TJ, Kook $\mathrm{H}$. Long-term follow-up of Fanconi anemia: clinical manifestation and treatment outcome. Korean J Pediatr 2014;57(3):125-34.
41. Zen PRG, Moraes FND, Rosa RFM, Graziadio C, Paskulin GA. Clinical characteristics of patients with Fanconi anemia. Rev Paul Pediatr 2011;29(3):392-9.

42. Malric A, Defachelles AS, Leblanc T, Lescoeur B, Lacour B, Peuchmaur $M$, Maurage CA, Pierron G, Guillemot D, d'Enghien CD, Soulier J. Fanconi anemia and solid malignancies in childhood: a national retrospective study. Pediatr Blood Cancer 2015;62(3):463-70

43. Kutler DI, Patel KR, Auerbach AD, Kennedy J, Lach FP, Sanborn E, Cohen MA, Kuhel WI. Smogorzewska A. Natural history and management of Fanconi anemia patients with head and neck cancer: A 10 year follow-up. Laryngoscope 2015;126(4):870-9.

44. Shimamura A, Alter BP. Pathophysiology and management of inherited bone marrow failure syndromes. Blood Rev 2010;24(3):101-22. 